\title{
Electrical production cost of young coconut waste pellet by using mini pellet mill-a feasibility study
}

\author{
Norain Idris ${ }^{1}$, Intan Mastura Saadon ${ }^{2}$, Aziean Mohd Azize ${ }^{3}$, Muhammad Zulfattah bin Zakaria ${ }^{4}$ \\ ${ }^{1}$ Faculty of Mechanical and Manufacturing Engineering Technology, Universiti Teknikal Malaysia Melaka, Malaysia \\ ${ }^{2,3}$ Faculty of Electrical and Electronic Engineering Technology, Universiti Teknikal Malaysia Melaka, Malaysia \\ ${ }^{4}$ Faculty of Mechanical Engineering, Universiti Teknikal Malaysia Melaka, Malaysia
}

\begin{tabular}{l} 
Article Info \\
\hline Article history: \\
Received Aug 25, 2019 \\
Revised Oct 27, 2019 \\
Accepted Nov 11, 2019 \\
\hline
\end{tabular}

Keywords:

Coconut

Pellet

Production cost

Young coconut

\begin{abstract}
Biomass from plants, which have lignocellulosic structure have low bulk density of $30 \mathrm{~kg} / \mathrm{m} 3$, is suitable to be pelletized to increase its specific density (gravity) for easy and inexpensive handling and storage. A new biomass waste material has evolved in interest due to abundant young coconut waste produced from famous young coconut drink and shake business in Melaka, Malaysia. The young coconut pelletization feasibility needs to be verified by firstly assessing its electrical production cost. Therefore, this paper aims to measure the electrical production cost for process involved in young coconut pelletization and analyze its competitiveness against other biomass material from other countries. This is executed by assessing the electrical production cost of three main process in pelletization; crushing, drying and pelleting. The equipments used are coconut crusher, lab-scaled industrial oven and mini pellet mill. The result demonstrates a significantly high electrical production cost, which is MYR141,430/tonne, while other material's production cost only amounts to couple of Malaysian hundreds. Processes' efficiency need to be massively improved by using drum drying method and by adding blender after crusher to increase the desired grain size to avoid raw material wastage. Electrical tariff must also be switched from commercial to industrial tariff.
\end{abstract}

Copyright $(2020$ Institute of Advanced Engineering and Science. All rights reserved.

\section{Corresponding Author:}

Norain Idris,

Faculty of Mechanical and Manufacturing Engineering Technology,

Universiti Teknikal Malaysia Melaka,

Jalan Hang Tuah Jaya, 76100 Durian Tunggal, Melaka, Malaysia.

Email: norain.idris@utem.edu.my

\section{INTRODUCTION}

Biomass from plants, which have lignocellulosic structure have low bulk density of $30 \mathrm{~kg} / \mathrm{m} 3$. Their moisture content range on wet basis are between $10 \%$ and $70 \%$. Pelleting, which is an alternative densification process to produce 6 to $8 \mathrm{~mm}$ in diameter and 10 to $12 \mathrm{~mm}$ long cylinder (pellet), increases the specific density (gravity) of biomass to more than $1000 \mathrm{~kg} / \mathrm{m} 3$ [1, 2]. Biomass is densified into pellets to ensure low and homogeneous moisture content throughout the pellets for inexpensive handling and decomposing avoidance during storage purpose [3, 4]. In Europe, solid biomass remains as the most essential part of biomass even though its share in overall contribution in biomass decreased constantly between year 2006 and 2017 [5].

Among popular biomasses that are densified into biomass pellets are wood, rice, wheat and corn waste $[6,7]$. Other famous biomass pellets in Malaysia are originated from wood, oil palm waste and old coconut coir [8-12]. According to [13], there are two techniques, which can be used to choose the most favourable plant for solid biopellet; Hierarchical Clustering Agglomerative and Principal Components. The enlarging market of pellet requires new material consideration beyond wood [14]. Therefore, a new 
biomass pellet material has evolved in interest as young coconut drink and shake is one of not only tourists' but also locals' main attraction in Melaka. Based on our previous conducted survey in three main provinces in Melaka, which are Melaka Tengah, Alor Gajah and Jasin, the young coconut waste is produced approximately 1 to 2 tonnes per week [15]. However, a feasibility study based on its production cost must be investigated beforehand to examine whether the price per energy unit from this source is competitive to other biomass energy sources such as wood and oil palm waste. This is an indicator to prove whether the pellet production from the young coconut waste is feasible or not.

The pelletization of biomass consists of a several processes: drying, size reduction, densifying, cooling, screening, and warehousing [3], [16]. According to [3], pellet production cost in North America for a base case plant capacity of $6 \mathrm{t} / \mathrm{h}$ was about $\$ 51 / \mathrm{t}$ of pellets, while pellet plants with a capacity of more than $10 \mathrm{t} / \mathrm{h}$ decreased the costs to roughly $\$ 40 / \mathrm{t}$ of pellets. The paper reported that the relationship between production cost and production capacity is exponentially decreasing correlated. Meanwhile, [17] revealed that briquette production cost, another type of solid biofuel ranged from $66.55 € \mathrm{t}-1$ to $137.87 € \mathrm{t}-1$ for rape straw briquettes and for those made from a mixture of rape straw and rapeseed oilcake (50:50), respectively in north-eastern Poland. In Canada, switchgrass pellet ranges from $\$ 72$ to $\$ 102 / \mathrm{t}$, whereby its drying cost is excluded, depending on its raw material cost [18]. Other than that, [19] published that cost of pellet production is between $\$ 78$ and $\$ 113 / \mathrm{t}$ in Sweden and Austria.

Pilot scale demonstration should be carried out to examine the scale up scenario and commercial viability [20]. However, this paper only focuses on young coconut waste pellet production processes by using a lab-scaled coconut crusher and pellet mill which has a production capacity of $20-30 \mathrm{~kg} / \mathrm{h}$. Despite the small size of the mini pellet mill, it has features seen on professional large scale professional pellet mills. It has a conditioning chamber, where crushed raw material will be mixed with any prestored liquid such as water and oil to either increase or reduce compression within the pellet mill die. It also features a ring die design which is used by most commercial pellet plants.

This paper calculates only electrical production cost and does not consider the capital cost of involved machines and excludes the feedstock logistic cost from collection, storage, production to users. [21] The production cost includes electricity utilization for the crushing, drying by using optimized temperature from [22] and pelleting processes, water and lubricant utilization for pelleting process (to adjust moisture level of the feedstock) and raw material cost (young coconut waste). The cost must be in range of other biomass pellet in order to be produced. Later on, biomass moisture can be further optimized in order to further reduce the production cost [23]. Moreover, an ecological tax is suggested to be increased on conventional fuel source such as coal or subsidy should be given to biomass pellet plant set up [12]. This project is hypothesized to prove the feasibility of biomass pellet production from a new biomass material, which is young coconut waste. The feasibility is proven by comparing the price per kWh of marketavailable biomass pellet or other biomass solid fuel like briquette with the new material (young coconut waste) pellet.

\section{METHODOLOGY}

\subsection{Complete Pelleting Process Overview}

In this study, the operation costs were present in a young coconut waste pellet production. The operation costs were related to cost of electricity consumption for operation. Generally, pellet operation has three main processes: Crushing process, drying process and pelleting process. In this study, the cost and energy consumption assessment utilize $963 \mathrm{kgs}$ raw material of young coconut waste. The total energy and cost used in the pellet production was determined by calculating from three main processes as shown in Figure 1. 


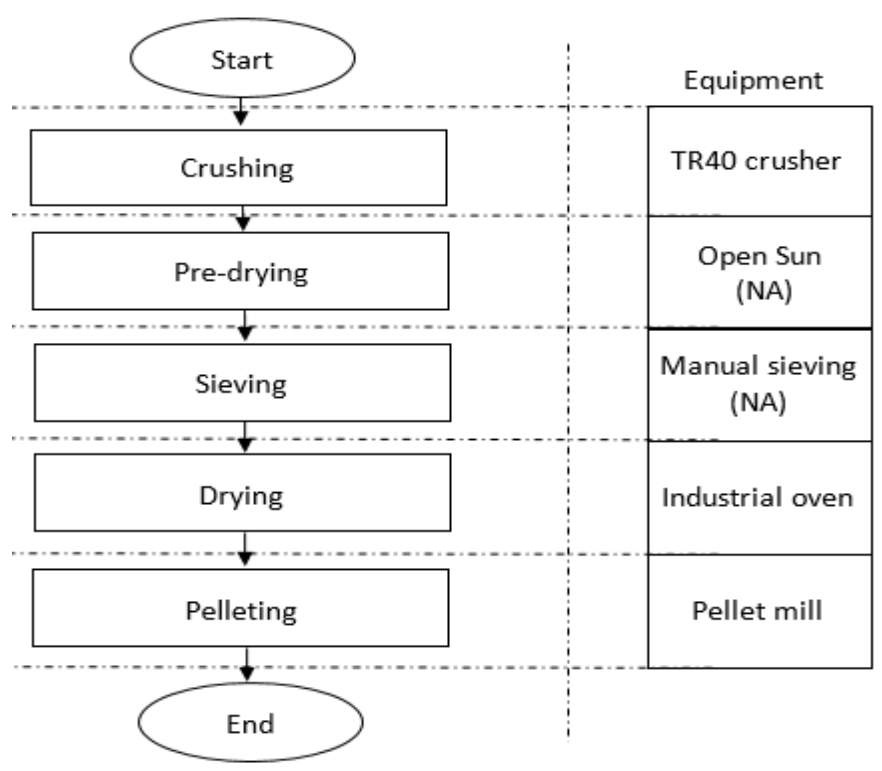

Figure 1. Flow chart of young coconut waste pelleting process

\subsection{Pelleting Process}

Young coconut waste (YCW) was collected from young coconut stalls in Melaka at several areas, mainly from Melaka Tengah region such as Batu Berendam and Bukit Katil. To get smaller grain size of material for the sieving and drying process, the young coconut waste was crushed for three times in coconut crusher Trapp TC40, which uses impact cutting, to increase yield of $<1 \mathrm{~mm}$-grain size. The crushed raw material went through a pre-drying for 123 hours under the Sun (Open-sun drying method) between 1000 to 1600 to decrease the moisture content to enable the raw material to be sieved. The pieces of young coconut waste were then manually sieved into the $<1 \mathrm{~mm}$-grain size. Approximately $11 \mathrm{kgs}$ of the $<1 \mathrm{~mm}$-grain size young coconut feedstock was produced from sieving and the feedstock were dried in a lab-scaled industrial oven at temperature of $95^{\circ} \mathrm{C}$. The process needs about 1603 hours to complete to get feedstock with moisture content of $9 \%$. About $4 \mathrm{kgs}$ of $9 \%$ moisture content-feedstock is produced and this quantity is the least amount, which is required by the mini pellet mill for the pelleting process. The dried feedstock fed into the mini pellet mill's hopper and its auger feed directs the feedstock into pelleting chamber, where the feedstock was compressed through holes from the inside face of a ring die. The pellets were extruded, and an adjustable knife cut the pellets off to desired length. This pelleting process took approximately 0.83 hour for $4 \mathrm{kgs}$ feedstock. Operation hour for pellet process as shown in Table 1.

Table 1. Operation Hour for Pellet Process

\begin{tabular}{ll}
\hline \multicolumn{1}{c}{ Process } & \multicolumn{1}{c}{ Operation duration (hours) } \\
\hline Raw material collection & N/A \\
Crushing & 37.04 \\
$\begin{array}{l}\text { Open-sun pre-drying (from 1000 to } \\
1600)\end{array}$ & 123.00 (N/A in the production cost calculation) \\
Sieving & N/A \\
Lab-scaled oven drying & 1603 (for approximately 11 kgs of <1 mm-grain to produce $4 \mathrm{kgs}$ \\
& of $9 \%$ moisture content-dried feedstock) \\
Pelleting & 0.83 (including the machine warming up) \\
\hline
\end{tabular}

\subsection{Energy and Cost Consumption Assessment}

The main equipment, which were used in pellet production processes are TC40 Trapp crusher, a labscaled industrial oven and a mini pellet mill with 20 to $30 \mathrm{kgs}$ production capacity per hour. The total electrical energy consumed corresponded to the mentioned equipment only. Figure 2 is steps to calculate the total energy and cost used in the young coconut waste pellet production. 


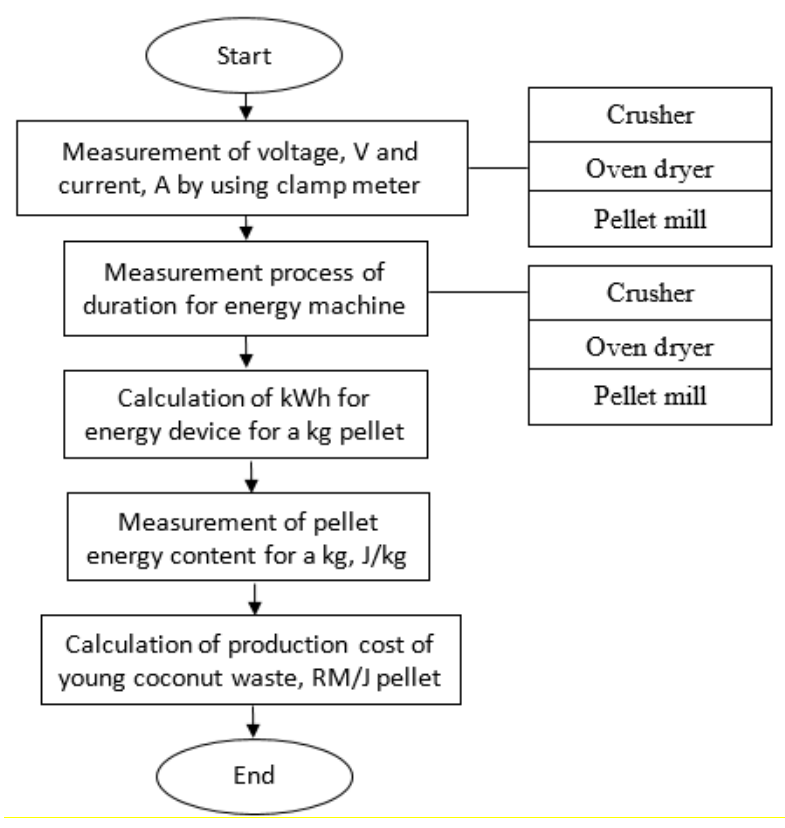

Figure 2. Flow chart of calculation for operation cost

The power requirement $(\mathrm{kW})$ was determined by recording the voltage and current by using clamp meter. Clamp meter measured the line current (I) and potential voltage (V) at three different machines while the machine is operating with load. The electrical power consumption was determined from measured current and voltage values as follows equation:

$$
P=V^{*} I^{*} \cos _{\mathrm{L}}^{\mathrm{r} f_{\mathrm{O}} \mathrm{i}} \theta
$$

Where:

$P$ : Electrical power, $\mathrm{kW}$

I: electric current, A

$V$ : electrical voltage, $\mathrm{V}$

$\operatorname{Cos} \theta$ : power factor being equal to $\cos 30^{\circ}: 0.86$

From electric power consumption amount, the energy consumption can be determined by multiply electrical power consumption with time, $\mathrm{kWh}$.

$$
E=\mathrm{P}^{*} \mathrm{t}
$$

Where:

$E$ : Electric energy, kWh

$P$ : Electrical power, $\mathrm{kW}$

$t$ : Time, h

The energy in (2) is calculated for $4 \mathrm{kgs}$ of $9 \%$ moisture content- feedstock due to the minimum production capacity of the mini pellet mill. The energy consumption per weight can be calculated by dividing electrical energy from (2) with mass of raw material.

For cost of energy, according to C2 tariff declared by Tenaga Nasional Berhad (TNB) in Malaysia, the price of kilowatt hour of electric are varies depending on peak and off hour. Since the pelleting processes were conducted during peak hour at Universiti Teknikal Malaysia Melaka laboratories, the price for all kWh during peak period is $36.50 \mathrm{cent} / \mathrm{kWh}$. Cost of electrical energy per weight as follows equation:

$$
\text { Cost/mass }=\text { Rate } * \text { E/mass }
$$

Where:

Cost/mass: Total electrical cost of machine operation per mass, MYR/kg

Rate: Energy cost per unit kWh, 36.50 cent/kWh (TNB tariff, C2)

E/mass: Electric energy per mass, $\mathrm{kWh} / \mathrm{kg}$

Indonesian J Elec Eng \& Comp Sci, Vol. 18, No. 2, May 2020 : 599 - 606 
The energy consumption for per unit pellet mass, $\mathrm{J} / \mathrm{kg}$ was determined by using bomb caloric meter. The final cost per joule can be calculated by multiplying the total electrical cost per mass, MYR/kg with the specific energy consumption, $\mathrm{J} / \mathrm{kg}$ as following equation:

Cost/Joule $=$ Cost $/$ weight $* 1 / \mathrm{e}$

Where:

Cost/Joule: Total electrical cost for operated machine per joule, MYR/Joule

Cost/weight: Total cost machine operated per weight, MYR/kg

$e$ : specific energy consumption, $\mathrm{J} / \mathrm{kg}$.

\section{RESULTS AND ANALYSIS}

Electrical production cost is calculated based on measured current, voltage and the corresponding operated machine duration. Results in Table 2 reveal that electrical cost per mass is MYR141.43/kg produced pellet. This is equivalent to MYR141,430/tonne young coconut waste pellet. The result is already foreseen, as a sum of $963 \mathrm{kgs}$ of raw material are needed in crushing process, just to obtain $11 \mathrm{kgs}$ of $<1 \mathrm{~mm}$-grain feedstock after underwent sun pre-drying and sieving process. The $11 \mathrm{~kg}-<1 \mathrm{~mm}$-grain feedstock is needed to produce $4 \mathrm{~kg}$-optimum moisture level feedstock, which has $9 \%$ moisture content. Four kilograms is the minimum production capacity of the mini pellet mill.

The evidence of the cause factors can be seen in following Figure 3. Oven drying process took significantly long duration if compared to other processes. This relates directly to the increment of electrical production cost. The drying process costs $96.85 \%$ from the total electrical production expenditure. This may be due to utilization of lab-scaled oven. Therefore, this process needs to be improved by switching to mass production, changing TNB tariff to industrial tariff and using large scale industrial drum dryer (other drying method) are expected to inevitably reduce the electrical drying cost. This fact is supported by [19] and [3]. Changing drying method to rotating drum drying is more suitable and cheaper for industrial mass production.

Apart of that, if crushing efficiency can be increased, the total electrical production cost can be most likely further reduced. This can be done by adding crushing frequency or addition of a blender after the crusher, as blender cuts, not crushes. This will result a higher amount of <1mm-grain feedstock. Despite of the smaller percent contribution to the total electrical cost, which is about $3 \%$, it is still significant if compared to the pelleting process, which only amounted to $0.00014 \%$. The $3 \%$ is equivalent to MYR 4,243/t. In addition, via increasing the crushing/ blending efficiency, lesser raw material will be needed to produce the same amount of feedstock for drying process.

Table 2. Operation Cost for Pellet Process

\begin{tabular}{|c|c|c|c|c|c|}
\hline Parameters & Crusher & Oven drying & Pellet mill (I) & Pellet mill (II) & Total \\
\hline Weight feedstock (kg) & 963.00 & 11.10 & 4.00 & 4.00 & N/A \\
\hline Current, I (Ampere) & 6.20 & 4.70 & 0.9 & 8.7 & N/A \\
\hline Voltage, V (volt) & 244.70 & 230.00 & 56.5 & 30 & N/A \\
\hline Operation duration, $\mathrm{t}$ (minutes) & 2222.30 & 96200.00 & 50.00 & 50.00 & N/A \\
\hline Operation duration, $\mathrm{t}$ (hours) & 37.04 & 1603.33 & 0.83 & 0.83 & N/A \\
\hline Power, P (watts) & 1313.88 & 936.17 & 44.04 & 226.03 & N/A \\
\hline Energy, E (kWh) & 48.66 & 1501.00 & 0.04 & 0.19 & 1549.89 \\
\hline Energy per mass, E/W $(\mathrm{kWh} / \mathrm{kg})$ & N/A & N/A & N/A & N/A & 387.47 \\
\hline $\begin{array}{l}\text { Electrical production cost per mass, } \\
(\mathrm{MYR} / \mathrm{kg})\end{array}$ & N/A & N/A & N/A & N/A & 141.43 \\
\hline Energy content, e $(\mathrm{J} / \mathrm{kg})$ & N/A & N/A & N/A & N/A & 16130.00 \\
\hline Production cost, (MYR/J) & N/A & N/A & N/A & N/A & 0.01 \\
\hline
\end{tabular}

The end electrical production cost per tonne of young coconut waste pellet is the highest among other biomass solid fuel due to extremely inefficient lab-scaled drying process. Moreover, initial moisture content of the raw material also impacts the drying duration and directly the cost. As a feedstock, young coconut waste is significantly wet if compared to switch grass, rape straw and other common pellet material like rice husk. The production price is also influenced by crushing performance.

The scenario is massively due to the involved small lab-scaled machines, unsuitable tariff (commercial tariff) and processes were executed at peak hour as the process is conducted at university's facility during the day. This is exhibited by the figure MYR141,430/tonne in Table 3. From the table, it can be extracted that other pellets/briquette's production cost only amounts to couple of Malaysian hundreds. 
This is more than $20 \mathrm{k}$ folds smaller than the young coconut pellet electrical cost. Different electrical tariff in distinct countries may be one of the root cause of various resulted production cost. However, it is to be noted that Table 3-displayed switch grass pellet production price per tonne in Canada excluded its drying cost.

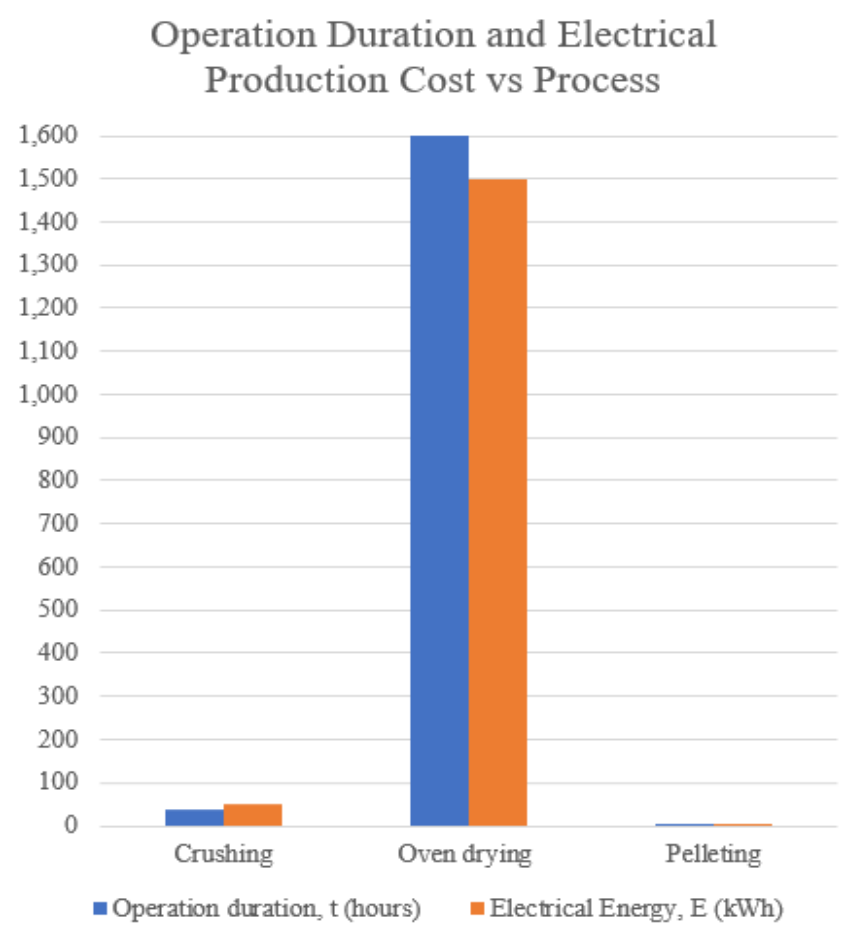

Figure 3. Machine operation duration and electrical production cost relation of every process

Table 3. Minimum and Maximum Production Price per Tonne for Biomass Solid Fuel (Pellet and Briquette) in Different Countries

\begin{tabular}{lcc}
\hline \multicolumn{1}{c}{ Country / Types of Solid Fuel } & $\begin{array}{c}\text { Min. Price per Tonne } \\
\text { MYR/t) }\end{array}$ & $\begin{array}{c}\text { Max. Price per Tonne } \\
\text { (MYR/t) }\end{array}$ \\
\hline Canada - Switch grass pellet (without drying) [14] & 284.62 & 403.21 \\
Sweden \& Austria - Pellet [15] & 308.33 & 446.69 \\
North-Eastern Poland - Rape straw briquette [20] & 356.28 & 738.09 \\
North America - Biomass Pellet [3] & 158.12 & 201.6 \\
Melaka, Malaysia - Young Coconut Waste Pellet & NA & $141,430.00$ \\
\hline
\end{tabular}

\section{CONCLUSION}

From the result data and analysis, there are several findings that can be listed out as following:

a) Processes' efficiency need to be massively improved by switching to most optimum methods to allow young coconut waste pelletization. Shocking reduction may be experienced by changing the drying method to the more optimum method, as drying cost dominates the total electrical cost. As for mass drying, rotating drum drying is the suggested method for the purpose.

b) The young coconut waste pellet electrical production cost is remarkably high. In pursuance of using the young coconut waste as new material, the type of utilized electrical tariff needs to be revised from commercial to industrial tariff.

c) To guarantee the young coconut waste feasibility, crushing process must also be improved by adding blender after crusher to increase yield of $<1 \mathrm{~mm}$-grain of feedstock and reduce the amount usage of raw material.

d) The production cost must be re-evaluated during mass young coconut waste pellet production to enable satisfying literature comparison. 


\section{ACKNOWLEDGEMENTS}

The authors wish to thank Ministry of Higher Education for funding the research grant PJP/2015/FTK(12A)/S01417 and also Universiti Teknikal Malaysia Melaka for providing all laboratory facilities.

\section{REFERENCES}

[1] Lehtikangas, P. (2001), "Quality properties of pelletised sawdust, logging residues and bark," Biomass and Bioenergy 20(5). pp. 351-360.

[2] D. P. Garcia, J. C. Caraschi, G. Ventorim, F. H. A. Vieira, and T. de Paula Protásio, "Assessment of plant biomass for pellet production using multivariate statistics (PCA and HCA)," Renew. Energy, vol. 139, pp. 796-805, 2019.

[3] Mani, Sudhagar \& Bi S. Sokhansanj, X \& Turhollow, Anthony. (2006), "Economics of producing fuel pellets from biomass," Applied engineering in agriculture. 22. pp. 1-6. 10.13031/2013.20447.MariuszJ. Stolarski et al, 2013

[4] K. Konrád, Z. J. Viharos, and G. Németh, "Evaluation, ranking and positioning of measurement methods for pellet production," Measurement, vol. 124, pp. 568-574, 2018.

[5] T. de la Fuente, D. Bergström, S. González-García, and S. H. Larsson, "Life cycle assessment of decentralized mobile production systems for pelletizing logging residues under Nordic conditions," J. Clean. Prod., vol. 201, pp. 830-841, 2018.

[6] Theerarattananoon, K., Xu, F., Wilson, J., Ballard, R., Mckinney, L., Staggenborg, S., ... Wang, D. (2011) ), "Physical properties of pellets made from sorghum stalk, corn stover, wheat straw, and big bluestem," Industrial Crops and Products, 33(2), pp.325-332.

[7] Belonio, A.T. \& Bhuiyan, M.A.. (2012), "Title: Design of a continuous - Type rice husk gasifier stove and power generation device for Bangladesh household". pp.1-6.

[8] Ahmed, T. Y., \& Ahmad, M. M. (2011), “ Equilibrium Model for S team Gasification of Palm Kernel Shell for Hydrogen Production."

[9] Atnaw, S. M., Sulaiman, S. a., \& Yusup, S. (2011), "Prediction of calorific value of syngas produced from oil-palm fronds gasification," [2011 National Postgraduate Conference, p. 1-4].

[10] Azlina, W., Ab, W., Ghani, K., Moghadam, R. A., Amran, M., \& Salleh, M. (2002). Air Gasification of Malaysia Agricultural Waste in a Fluidized Bed Gasifier. Hydrogen Production Performance.

[11] Sabri, M., Mukhtar, A., Shahril, K., Rohana, A. S., \& Salmah, H. (2013). Effect of Compatibilizer on Mechanical Properties and Water Absorption Behaviour of Coconut Fiber Filled Polypropylene Composite. Advanced Materials Research. 795. pp. 313-317.

[12] Shafie, S. M., Mahlia, T. M. I., Masjuki, H. H., \& Ahmad-Yazid, A. (2012). A review on electricity generation based on biomass residue in Malaysia. Renewable and Sustainable Energy Reviews. 16(8). pp. 5879-5889.

[13] T. Králík, J. Knápek, L. Dvořáček, and K. Vávrová, "Impact of pelleting cost on competitiveness of intentionally grown biomass for local space heating: Case example of the Czech Republic," Energy Reports, 2019.

[14] H. Shahrukh, A. O. Oyedun, A. Kumar, B. Ghiasi, L. Kumar, and S. Sokhansanj, "Techno-economic assessment of pellets produced from steam pretreated biomass feedstock," Biomass and Bioenergy, vol. 87, pp. 131-143, 2016.

[15] Zamri N.D.M., Norain I., Mitan N.M.M., Muhammad N.1, Zulfattah Z.M.1, Forzaima A.R., Masripan N.A.B.1, "Young Coconut Waste Pellet Feasibility Prediction - A Survey In Melaka," ARPN Journal of Engineering and Applied Sciences, submitted for publication.

[16] P. Pradhan, S. M. Mahajani, and A. Arora, "Production and utilization of fuel pellets from biomass: A review," Fuel Process. Technol., vol. 181, pp. 215-232, 2018.

[17] Mariusz J. Stolarski, Stefan Szczukowski, Józef Tworkowski, Michał Krzyżaniak, Paweł Gulczyński, Mirosław Mleczek (2013), "Comparison of quality and production cost of briquettes made from agricultural and forest origin biomass, ” Renewable Energy, Volume 57. pp. 20-26.

[18] Samson, P., P. Duxbury, M. Drisdelle, C. Lapointe. (2000). Assessment of pelletized biofuels. Available: http://www.reap-canada.com/online_library/feedstock_biomass/15\%20Assessment\%20of.PDF. Accessed on 15th May 2018.

[19] Thek, G., and I. Obernberger. (2004). Wood pellet production costs under Austrian and in comparison to Swedish framework conditions. Biomass and Bioenergy. 27(6). pp. 671-693

[20] Mani, S., L. G. Tabil, and S. Sokhansanj. (2004). Evaluation of compaction equations applied to four biomass species. Canadian Biosystems Engineering. 46(1). pp. 3.55-3.61.

[21] K. Ishii, T. Furuichi, A. Fujiyama, and S. Watanabe, "Logistics cost analysis of rice straw pellets for feasible production capacity and spatial scale in heat utilization systems: A case study in Nanporo town, Hokkaido, Japan," Biomass and Bioenergy, vol. 94, pp. 155-166, 2016.

[22] Norain Idris, Mohd Azwar bin Azhari, Nur Dalilah Mohd Zamri, Muhammad Zulfattah bin Zakaria, Intan Mastura Saadon, Halyani bin Mohd Yassim, "Temperature Optimization of Young Coconut Waste Pellet Feedstock via Oven Drying Method - A FTIR and SEM Analysis," unpublished.

[23] L. Chai and C. M. Saffron, "Comparing pelletization and torrefaction depots: Optimization of depot capacity and biomass moisture to determine the minimum production cost," Appl. Energy, vol. 163, pp. 387-395, 2016. 


\section{BIOGRAPHIES OF AUTHORS}
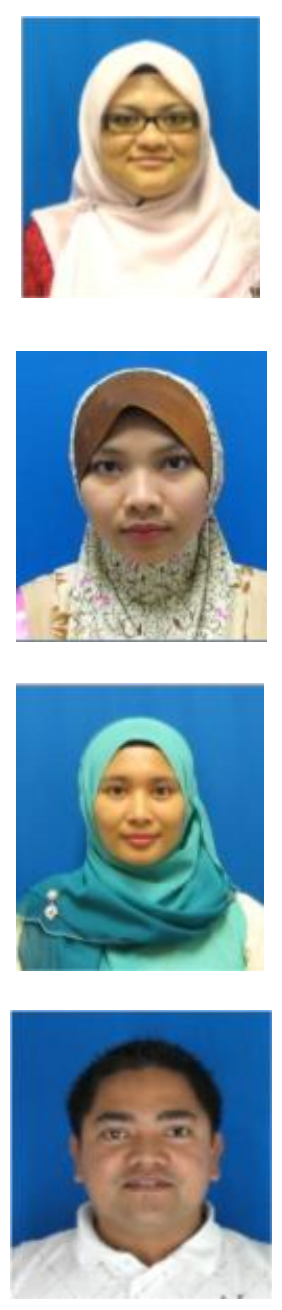

Norain Idris received her B. Eng degree in Mechanical Engineering (Production) in 2010 from Fachhochschule Frankfurt am Main, Germany and M. Eng in Mechanical Engineering from Universiti Malaya (UM). Currently she is a lecturer at Universiti Teknikal Malaysia Melaka (UTeM) and her interest involves renewable energy and green technology.

Intan Mastura Saadon received her B. Eng degree in Electrical Engineering (Instrumentation \& Control) in 2008 from Universiti Teknologi Malaysia (UTM) and M. Eng in Electrical Engineering from Universiti Malaya (UM). Currently she is a lecturer at Universiti Teknikal Malaysia Melaka (UTeM) and her interest involves renewable energy.

Aziean Mohd Azize received her B. Eng degree in Electrical Engineering and $\mathrm{MsC}$ in Telecommunication and Information Engineering from Universiti Teknologi Mara Malaysia (UiTM). Currently she is a lecturer at Universiti Teknikal Malaysia Melaka (UTeM) and her interest involves microwave and green technology.

Muhammad Zulfattah Zakaria received his B. Eng degree in Mechanical Engineering in 2008 from Fachhochschule Ruesselsheim, Germany and M. Eng in Energy System from Fachhochschule Aachen, Germany. Currently he is a senior lecturer at Universiti Teknikal Malaysia Melaka (UTeM) and his interest involves renewable energy and green technology. 